\title{
Interprofessional Education Research: Disciplines, Authorship Practices, Research Design, and Dissemination Trends
}

\section{Amanda A. Olsen}

The University of Texas at Arlington

Carly P. Lupton-Smith

Johns Hopkins University

Gary L. Beck Dallaghan

University of North Carolina at Chapel Hill

Jacqueline E. McLaughlin ( $\nabla$ Jacqui_mclaughlin@unc.edu )

University of North Carolina at Chapel Hill

\section{Research Article}

Keywords: Interprofessional education, research methods, review, authorship

Posted Date: February 1st, 2022

DOI: https://doi.org/10.21203/rs.3.rs-1280218/v1

License: (c) (i) This work is licensed under a Creative Commons Attribution 4.0 International License.

Read Full License 


\section{Abstract}

Background: In 2007, the World Health Organization launched the Programme on Interprofessional Education and Collaborative Practice to emphasize the importance of interprofessional education (IPE). Since then, numerous IPE reviews have focused on what has been implemented and evaluated. The purpose of this review was to explore how IPE has been implemented and evaluated.

Methods: The following aspects of IPE research were explored: 1) disciplines included; 2) authorship patterns, 3) assessment focus, and 4) dissemination trends. Abstracts were screened before a full text screening, review, data extraction, analysis and audit. Frequency and percentages were reported for categorical data while means and standard deviations were reported for continuous data. Chi-squared analyses examined differences between groups for categorical variables.

Results: Three-hundred and fifty-nine articles met the inclusion criteria. Authors from medical, nursing, and pharmacy schools published most frequently, with a majority using quantitative or mixed-methods techniques. Most studies involved a student discipline without an author from that discipline. Most studies also evaluated student perceptions. Studies were published in 98 journals, most of which were interdisciplinary journals, with the largest increase in publications in the most recent year of the review.

Conclusion: IPE research has grown substantially over the past 10 years. Consideration should be given to expanding IPE research methodologies, strategically publishing IPE findings, and promoting authorship representation for student disciplines involved in IPE.

\section{Background}

In 2007, the World Health Organization (WHO) launched the Programme on Interprofessional Education and Collaborative Practice to emphasize interprofessional education (IPE) and identify mechanisms that facilitate successful interprofessional collaborations [1]. IPE opportunities occur when students from more than one health profession (i.e., medicine, dentistry, nursing, pharmacy, etc.) learn interactively together to strengthen interprofessional collaboration and improve patient care outcomes [2]. Evidence suggests that patients receive higher quality care when health care professionals understand each other's respective roles, facilitating higher quality communication and teamwork $[3,4,5]$.

Numerous reviews have addressed the topic of IPE $[2,6,7,8]$. Specifically, researchers have focused on the relationships between different health professions such as nursing, medicine, or pharmacy, or on the overall effectiveness of IPE on student learning outcomes $[2,6,7,8]$. While others have explored what has been studied in IPE, few have analyzed how it has been studied.

The multidisciplinary edge effect framework posits that researchers build their knowledge based on specific lenses, assumptions, and paradigms central to the researcher's home discipline [9]. This can be complex for IPE initiatives since research teams are often composed of individuals from disciplines that subscribe to contrasting paradigms and methodologies [9]. In turn, this can influence research questions, 
designs, and analyses used to study IPE $[10,11,12,13,14]$. Characterizing the core research elements of IPE research can help elucidate ways in which IPE has been studied and further inform opportunities for advancing IPE. Therefore, the purpose of this study was to investigate: 1) disciplines included in IPE research; 2) authorship practices; 3 ) assessment focus, and 4) dissemination trends.

\section{Methods}

The search terms for this review were "interprofessional education" AND student, which we selected to provide the most comprehensive selection of IPE research articles across all health professions disciplines. Studies were included if they: involved student participants from the United States; were published in peer-reviewed journals; and contained an IPE opportunity where students engaged, collaborated, participated, and/or exchanged ideas with students from at least one different health profession. In addition, we included studies published beginning in 2008, which was the year following the launch of the WHO Programme on Interprofessional Education and Collaborative Practice [1]. We excluded studies that solely reviewed the literature (e.g., meta-analysis, systematic review, literature review, etc.), were not written in English, were not peer-reviewed (e.g., commentaries, dissertations, book chapters, etc.), or were designed exclusively to validate a measure or instrument.

Databases included PubMed, SCOPUS, PsycINFO, Excerpta Medica database (EMBASE), Medical Literature Analysis and Retrieval System Online (MEDLINE), and the Education Resources Information Center (ERIC). PubMed, SCOPUS, EMBASE, and MEDLINE are common databases that have been frequently used in other IPE reviews $[2,6,7,8]$. ERIC was selected to find additional education articles, since it is the largest education database in the world [15], and PsycINFO was selected to capture IPE research published in education and the social science journals. In addition, we hand searched the Journal of Interprofessional Care to capture any missing articles. Journal articles were cataloged in Mendeley (London, United Kingdom), a reference management software, and uploaded into Covidence (Melbourne, Australia), a software used for article screening, data abstraction, and quality assessment. We started and completed the search in October of 2018 (see Table 1). 
Table 1

Characteristics of IPE Studies ( $N=359)$, by Profession, from 2008 to 2018

\begin{tabular}{|c|c|c|c|c|c|c|}
\hline Profession & $\begin{array}{l}\text { Studies } \\
\text { Authored^ }^{\wedge} \\
\text { N (\%) }\end{array}$ & $\begin{array}{l}\text { Studies } \\
\text { as First } \\
\text { Author, } \\
\text { Total } \\
\text { N (\%) }\end{array}$ & $\begin{array}{l}\text { Studies } \\
\text { as Last } \\
\text { Author, } \\
\text { Total } \\
\text { N (\%) }\end{array}$ & $\begin{array}{l}\text { Studies as } \\
\text { First Author, } \\
\text { by } \\
\text { Authorship! } \\
\mathrm{N}(\%)\end{array}$ & $\begin{array}{l}\text { Studies as } \\
\text { Last } \\
\text { Author, } \\
\text { by } \\
\text { Authorship! } \\
\mathrm{N}(\%)\end{array}$ & $\begin{array}{l}\text { Student } \\
\text { Participants^ } \\
\mathrm{N}(\%)\end{array}$ \\
\hline $\begin{array}{l}\text { More than } 1 \\
\text { Profession }\end{array}$ & $\begin{array}{l}310 \\
(86.35 \%)\end{array}$ & - & - & - & - & $359(100 \%)$ \\
\hline Nursing & $\begin{array}{l}195 \\
(54.32 \%)\end{array}$ & $\begin{array}{l}94 \\
(26.18 \%)\end{array}$ & $\begin{array}{l}72 \\
(20.40 \%)\end{array}$ & $94(48.21 \%)$ & $\begin{array}{l}72 \\
(36.92 \%)\end{array}$ & $\begin{array}{l}252 \\
(70.19 \%)\end{array}$ \\
\hline Medicine & $\begin{array}{l}166 \\
(46.24 \%)\end{array}$ & $\begin{array}{l}69 \\
(19.22 \%)\end{array}$ & $\begin{array}{l}84 \\
(24.40 \%)\end{array}$ & $69(41.57 \%)$ & $\begin{array}{l}85 \\
(51.20 \%)\end{array}$ & $\begin{array}{l}227 \\
(63.23 \%)\end{array}$ \\
\hline Pharmacy & $\begin{array}{l}148 \\
(41.23 \%)\end{array}$ & $\begin{array}{l}68 \\
(18.94 \%)\end{array}$ & $\begin{array}{l}49 \\
(13.88 \%)\end{array}$ & 68 (45.95\%) & $\begin{array}{l}49 \\
(33.11 \%)\end{array}$ & $\begin{array}{l}187 \\
(52.09 \%)\end{array}$ \\
\hline Not-health* & $\begin{array}{l}111 \\
(30.92 \%)\end{array}$ & $\begin{array}{l}26 \\
(7.24 \%)\end{array}$ & $\begin{array}{l}43 \\
(12.18 \%)\end{array}$ & $26(23.42 \%)$ & $\begin{array}{l}43 \\
(38.74 \%)\end{array}$ & 42 (11.70\%) \\
\hline $\begin{array}{l}\text { Health } \\
\text { Support* }\end{array}$ & $\begin{array}{l}109 \\
(30.36 \%)\end{array}$ & $\begin{array}{l}33 \\
(9.19 \%)\end{array}$ & $\begin{array}{l}30 \\
(8.50 \%)\end{array}$ & 33 (30.28\%) & $\begin{array}{l}30 \\
(27.52 \%)\end{array}$ & $\begin{array}{l}135 \\
(37.60 \%)\end{array}$ \\
\hline Physiotherapy & $\begin{array}{l}75 \\
(20.89 \%)\end{array}$ & $\begin{array}{l}26 \\
(7.24 \%)\end{array}$ & $\begin{array}{l}27 \\
(7.65 \%)\end{array}$ & $26(34.67 \%)$ & $\begin{array}{l}27 \\
(36.00 \%)\end{array}$ & $\begin{array}{l}119 \\
(33.15 \%)\end{array}$ \\
\hline $\begin{array}{l}\text { Occupational } \\
\text { Therapy }\end{array}$ & $\begin{array}{l}44 \\
(12.26 \%)\end{array}$ & $\begin{array}{l}13 \\
(3.62 \%)\end{array}$ & $\begin{array}{l}10 \\
(2.83 \%)\end{array}$ & $13(29.55 \%)$ & $\begin{array}{l}10 \\
(22.73 \%)\end{array}$ & 79 (22.01\%) \\
\hline Dentistry & $\begin{array}{l}33 \\
(9.19 \%)\end{array}$ & 7 (1.94\%) & $8(2.27 \%)$ & 7 (21.21\%) & $8(24.24 \%)$ & $67(18.66 \%)$ \\
\hline $\begin{array}{l}\text { Physician } \\
\text { Assistance }\end{array}$ & $\begin{array}{l}27 \\
(7.52 \%)\end{array}$ & $2(0.56 \%)$ & 9 (2.55\%) & $2(7.41 \%)$ & 9 (33.33\%) & $59(16.43 \%)$ \\
\hline Audiology & $\begin{array}{l}22 \\
(6.13 \%)\end{array}$ & $7(1.94 \%)$ & $7(1.98 \%)$ & 7 (31.82\%) & 7 (31.82\%) & 40 (11.14\%) \\
\hline Other Health & $\begin{array}{l}21 \\
(5.85 \%)\end{array}$ & $7(1.94 \%)$ & $6(1.70 \%)$ & 7 (33.33\%) & $6(28.57 \%)$ & 47 (13.09\%) \\
\hline
\end{tabular}

*"Health Support" refers to supporting professions (e.g. social work, clinical psychology); "Not-health" includes non-health fields (e.g. educational researchers, statisticians). "Other health" included professionals like respiratory therapists.

!Percent based on all studies for that profession (i.e. studies authored)

^Studies may include individuals from multiple professions, therefore percentages may sum to exceed 100\%; "More than 1 Profession" not included in Total 


\begin{tabular}{|c|c|c|c|c|c|c|}
\hline Profession & $\begin{array}{l}\text { Studies } \\
\text { Authored^ }^{\wedge} \\
\mathrm{N}(\%)\end{array}$ & $\begin{array}{l}\text { Studies } \\
\text { as First } \\
\text { Author, } \\
\text { Total } \\
\text { N (\%) }\end{array}$ & $\begin{array}{l}\text { Studies } \\
\text { as Last } \\
\text { Author, } \\
\text { Total } \\
\text { N (\%) }\end{array}$ & $\begin{array}{l}\text { Studies as } \\
\text { First Author, } \\
\text { by } \\
\text { Authorship! } \\
\mathrm{N}(\%)\end{array}$ & $\begin{array}{l}\text { Studies as } \\
\text { Last } \\
\text { Author, } \\
\text { by } \\
\text { Authorship! } \\
\mathrm{N}(\%)\end{array}$ & $\begin{array}{l}\text { Student } \\
\text { Participants^ } \\
\text { N (\%) }\end{array}$ \\
\hline Dietetics & $\begin{array}{l}17 \\
(4.74 \%)\end{array}$ & $6(1.67 \%)$ & $5(1.42 \%)$ & $6(35.29 \%)$ & $5(29.41 \%)$ & 38 (10.58\%) \\
\hline Midwifery & $3(0.84 \%)$ & $1(0.28 \%)$ & $1(0.28 \%)$ & 1 (33.33\%) & 1 (33.33\%) & $5(1.39 \%)$ \\
\hline $\begin{array}{l}\text { Environmental } \\
\text { Health }\end{array}$ & $3(0.84 \%)$ & $0(0 \%)$ & $1(0.28 \%)$ & $0(0.00 \%)$ & 1 (33.33\%) & $2(0.56 \%)$ \\
\hline Optometry & $0(0 \%)$ & $0(0 \%)$ & $0(0 \%)$ & $0(0.00 \%)$ & $0(0 \%)$ & $2(0.56 \%)$ \\
\hline Total & 974 & 359 & 352 & 359 & 353 & 1301 \\
\hline \multicolumn{7}{|c|}{$\begin{array}{l}\text { *"Health Support" refers to supporting professions (e.g. social work, clinical psychology); "Not-health" } \\
\text { includes non-health fields (e.g. educational researchers, statisticians). "Other health” included } \\
\text { professionals like respiratory therapists. }\end{array}$} \\
\hline \multicolumn{7}{|c|}{ 'Percent based on all studies for that profession (i.e. studies authored) } \\
\hline $\begin{array}{l}\wedge \text { Studies may } \\
\text { exceed } 100 \% ;\end{array}$ & $\begin{array}{l}\text { de individ } \\
\text { re than } 1 \mathrm{P}\end{array}$ & $\begin{array}{l}\text { Is from } m \\
\text { fession" } n\end{array}$ & $\begin{array}{l}\text { ple profes } \\
\text { ncluded in }\end{array}$ & $\begin{array}{l}\text { is, therefore } \\
\text { tal }\end{array}$ & entages ma & sum to \\
\hline
\end{tabular}


Table 1

(cont). Characteristics of IPE Studies ( $\mathrm{N}=359$ ), by Profession, from 2008 to 2018

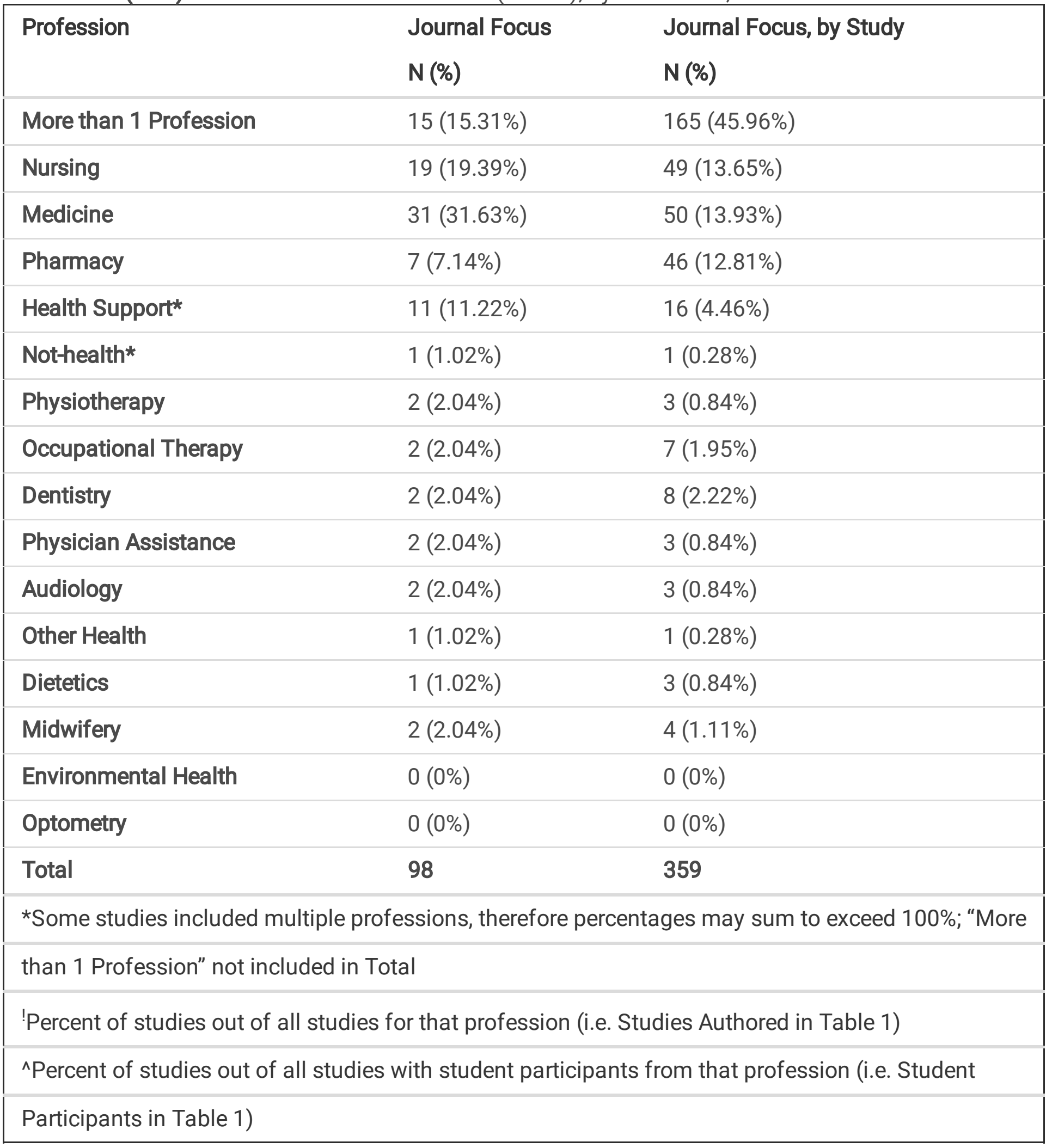

Variables of interest for this study included: author discipline, student discipline, research design, assessment focus (e.g., student perceptions, faculty perceptions, and student knowledge), and journal type (e.g., IPE or discipline-specific journal). We analyzed author order since the first author in health professions research is commonly considered the main contributor and the last or senior author is 
generally responsible for providing guidance to the research team, making author position an important factor in the clinical disciplines [16]. Authors were categorized using their credentials (PharmD, MD, etc.), their university affiliation, their university biography and/or their Google Scholar or ResearchGate account. In addition, author and student disciplines were classified according to the WHO categorizations [1]. "Health support" was used to group professions such as social work or clinical psychology, "other health" included respiratory therapists, while "not-health professionals" was used to group non-health professions such as educational researchers and statisticians. Further, the categories included all possible degree holders within those categories, meaning that medicine, for example, would include individuals who were either Medical Doctors (MD), Doctors of Osteopathic Medicine (DO), or Doctors of Philosophy (Ph.D.) working in medical schools.

Two investigators each extracted data from half of the articles. A third investigator conducted an independent audit on $15 \%$ of randomly selected articles, resulting in more than $95 \%$ agreement across the variables of interest. We present the results as frequency (percent) for categorical data and mean (standard deviation $\pm \mathrm{SD}$ ) for continuous data. We also used chi-square analyses to examine differences between groups for categorical variables. We considered a $p$-value $<.05$ as statistically significant.

\section{Results}

As seen in Figure 1, 3,058 articles were imported for screening. After we removed the duplicates, 1,518 abstracts were reviewed and 680 articles were advanced to full text screening. Conflicts regarding inclusion in the study were resolved by a third reviewer. There were 359 articles that met the inclusion criteria and were included in the review.

The authors of the reviewed articles represented 14 disciplines, including nursing, medicine, pharmacy, health support, dentistry, occupational therapy, midwifery, physiotherapy, audiology, physician assistance, dietetics, not-health, environmental health, and other health disciplines (Table 1). On average, there were $5.19 \pm 2.52$ authors per article with an average of $2.73 \pm 1.29$ different disciplines per article. The highest number of authors on a single article was 14 , while 7 articles $(1.95 \%)$ included only one author. Most articles had authors representing multiple disciplines $(n=310,86.35 \%)$. Articles with a pharmacist author averaged $6.12 \pm 2.71$ authors and $3.30 \pm 1.52$ author disciplines. Medical practitioners averaged $6.06 \pm$ 2.60 authors and $3.59 \pm 1.47$ disciplines per article, while nursing professionals averaged $5.55 \pm 2.57$ authors and $3.10 \pm 1.46$ author disciplines per article.

Nursing professionals authored 195 of the articles (54.32\%), followed by medical practitioners $(n=166$, $46.24 \%$ ), and pharmacists ( $n=148,41.23 \%)$. Authors from non-health fields ( $n=111,30.92 \%)$, such as statisticians and educational researchers and health support fields $(n=109,230.36 \%)$, such as social work and psychology were the fourth and fifth most published groups. Nursing professionals were the most frequent first authors $(n=94,26.18 \%)$, followed by medical practitioners $(n=69,19.22 \%)$ and pharmacists $(n=68,18.94 \%)$. In studies that included a nursing professional $(n=195)$ as an author, a nurse served as first author $48.21 \%(n=94)$ of the time, followed by $45.95 \%$ for studies with a pharmacist author $(n=68$ out 
of 148 articles), and medical practitioners at $41.57 \%$ ( $n=69$ out of 166 articles). Physician assistant authors had the lowest percentage of first authorship in articles authored by the profession at $7.41 \%$ ( $n=2$ out of 27 articles).

Medical practitioners were most frequently last author ( $n=85$ out of 166 articles, $51.20 \%$ ). Authors from non-health professions and nursing served as last authors $38.74 \%$ ( $n=43$ out of 111 articles) and $36.92 \%$ ( $n=72$ out of 195 articles) of the time, respectively. Occupational therapy had the lowest presence of last authorship in articles authored by the profession at $22.72 \%$ ( $n=10$ out of 44 articles). Chi-square tests reveal a significant association between discipline and author position (first or last) for the 5 most frequent authorship disciplines (nursing, medicine, pharmacy, health support, not-health), as these categories had a sufficiently large sample size for analysis $(\mathrm{p}=.01)$. Nursing professionals and pharmacists were more likely to be first authors while medical practitioners and not-health professionals were more likely to be last authors.

Fifteen student disciplines were involved as participants in IPE across all studies, with an average of 3.91 \pm 2.45 student disciplines per article. Nursing students were most frequently involved $(n=252,70.19 \%)$, followed by studies involving medical students $(n=227,63.23 \%)$, pharmacy students $(n=187,52.09 \%)$, health support students $(n=135,37.60 \%)$, and physiotherapy students $(n=119,33.15 \%)$.

When comparing student and author disciplines, a majority of articles contained a mismatch, when a student discipline was included in a study without an author from that discipline ( $n=190,53.92 \%)$. Twelve disciplines had more studies involving student participants than studies with authors. Studies including medical students, for example, lacked an author from medicine $31.44 \%$ of the time ( $n=72$ out of 229 articles), with pharmacy and nursing following at $25.13 \%$ ( $N=47$ out of 187 articles) and $24.60 \%$ ( $n=62$ out of 252 articles), respectively. Physiotherapy students were involved in $33.15 \%$ of studies, yet physiotherapy authors were only included in $20.89 \%$ of studies. In contrast, authors from environmental health and not-health authored more studies than they had students as participants. Not-health professionals, for example, authored $30.92 \%$ of articles ( $n=111$ articles) while not-health students were in only $11.70 \%$ of articles ( $n=42$ articles).

Regarding the analytic techniques used to study IPE, 150 (41.78\%) utilized mixed-methods, 147 (40.95\%) used quantitative and $62(17.27 \%)$ used qualitative. For the quantitative and mixed-methods studies, nearly all studied student perceptions $(n=279,93.94 \%)$ while few studied faculty perceptions $(n=25$, $8.42 \%)$ or student knowledge ( $n=78,27.96 \%)$. These categories were not mutually exclusive, meaning that a study could include both student and faculty perceptions for example.

IPE studies were published in 98 different journals. Nearly half $(n=165,45.96 \%)$ were published in 15 different interprofessional journals (e.g., Journal of Interprofessional Care). Although $31.63 \%$ of the journals were medicine-focused $(n=31)$ and $19.39 \%$ were nursing-focused $(n=19)$, only $13.62 \%$ and $13.65 \%$ of the articles were published in medicine and nursing journals, respectively. Similarly, physiotherapy students were involved in 119 IPE studies (33.15\%) yet only $3(0.84 \%)$ of these studies were published in physiotherapy-specific journals. Furthermore, individuals classified as not-health 
professionals were prevalent authors $(n=111,30.92 \%)$, yet only $1(0.28 \%)$ study involving a not-health professional was published in a not-health journal.

Longitudinally, the number of IPE studies increased over 2,000\% from 4 articles in 2008 to 90 in 2018 (Figure 2). With the exception of a slight decrease in the number of IPE studies from 2015 ( $n=57)$ to 2016 $(n=55,-3.51 \%)$, the number of IPE studies has increased each year. Notable increases occurred from 2011 $(n=7)$ to $2012(n=17 ; 142.86 \%$ increase), $2013(n=23)$ to $2014(n=35 ; 52.17 \%$ increase), and $2014(n=35)$ to $2015 n=57 ; 62.86 \%$ increase). More recently, IPE publications increased $52.54 \%$ from 59 in 2017 to 90 in 2018. As seen in Table 2, nursing authorship increased from 2 to 49 articles, pharmacy authorship from 1 to 46, and medical practitioner authorship from 1 to 50 during this time period (2008-2018). Occupational therapists began authoring IPE publications in 2009, with dentists and physician assistants following in 2012.

Table 2

Number of IPE Publications, by Year, for the Most Frequent First Author Disciplines

\begin{tabular}{|lllllll|}
\hline Year & All Disciplines & Nursing & Medicine & Pharmacy & Health Support & Not-health \\
\hline 2008 & 4 & 2 & 1 & 1 & 1 & 4 \\
\hline 2009 & 6 & 4 & 5 & 3 & 2 & 3 \\
\hline 2010 & 6 & 3 & 3 & 3 & 1 & 2 \\
\hline 2011 & 7 & 3 & 5 & 2 & 2 & 1 \\
\hline 2012 & 17 & 5 & 6 & 7 & 7 & 6 \\
\hline 2013 & 23 & 15 & 9 & 12 & 8 & 7 \\
\hline 2014 & 35 & 15 & 19 & 14 & 12 & 15 \\
\hline 2015 & 57 & 32 & 34 & 20 & 13 & 23 \\
\hline 2016 & 55 & 33 & 24 & 28 & 18 & 11 \\
\hline 2017 & 59 & 32 & 24 & 16 & 15 & 20 \\
\hline 2018 & 90 & 52 & 35 & 38 & 28 & 19 \\
\hline Total & 359 & 196 & 165 & 144 & 107 & 111 \\
\hline
\end{tabular}

\section{Discussion}

Providing IPE is critical for preparing aspiring healthcare providers for the complexities and realities of team-based care [17]. Research suggests that IPE can enable knowledge and skills necessary for teambased care, and is frequently used to enhance practice models and healthcare services [18]. We have extended previous IPE reviews by exploring the multidisciplinary edge effect and characterizing core research elements of published IPE in an effort to better understand how, and by whom, IPE has been 
studied and published [9]. Specifically, we examined the author and student disciplines engaged in IPE, along with research designs and journal characteristics.

IPE and its related research has grown significantly since the WHO Programme on Interprofessional Education and Collaborative Practice was launched in 2007 [1]. Historical calls for collaborative practice date back more than 30 years $[17,19]$, yet we have shown substantial increases in IPE research over the past decade. Possible explanations include increased adoption of the term "interprofessional education," increased implementation of IPE across health professions, increased numbers of professions engaged in IPE, growth in the number of health professions schools and associated personnel, and increased numbers of educators engaged in the scholarship of teaching and learning (SoTL) [20].

Most frequently, IPE research involved authors and students from nursing, medicine, and pharmacy. These are the oldest health professions and the most likely to interact due to proximity and job responsibilities, especially in inpatient medical settings [21]. Lawlis et al. also noted logistical barriers related to scheduling IPE activities and challenges of varying academic calendars across health professions schools [22]. These barriers are less prevalent for nursing, medicine, and pharmacy working in close proximity, which may enable IPE and IPE research between these groups. Engaging additional professions in IPE may require explicit efforts to reduce barriers to interaction between professions and their trainees.

We found the prevalence of mismatches between author and student disciplines uncovered in this review as somewhat surprising. The most common and potentially problematic mismatch occurred when students from a discipline were included in a study without an author from the same discipline. Since health professionals are trained in a tradition that aligns with the responsibilities of that profession [23, 24], a study lacking authorship representation could suffer from limited interpretation and subsequent impact. Said differently, IPE research with ghost authorship at the level of a discipline may fail to sufficiently evaluate, interpret, and discuss the implications of IPE outcomes for a discipline specifically or for healthcare broadly. It leaves some question as to whether the IPE activity adequately addressed and discussed the needs of the students from the profession without the contribution of an author from the same profession.

Along the same lines, other professions such as occupational therapy or dentistry may be less involved in this body of research due to fewer number of schools and students, or scarcer requirements for scholarly work as part of academic appointments [25]. Incentives for educators to engage in SoTL and publicly disseminate IPE findings could be an important strategy for increasing engagement in IPE research [26]. In addition, educators have responded to the WHO's call for more IPE by establishing collaborative committees and providing resources to prioritize interprofessional collaborations [22], which highlights the importance of international and national advocacy for the engagement of various health professions in IPE and IPE research.

Within IPE research collaborations, medical practitioners were more likely to be last author. This may be reflective of medicine's leading role in promoting IPE and related research. Alternatively, it could reflect the 
perception that the physician is responsible for the health care team and thus assigned the senior author position [27]. This is a well-documented challenge in dissemination, also called gift authorship [16, 28]. If this is the case, to improve transparency and integrity in IPE, authorship should be established based on contribution to the study from beginning to end, addressing authorship issues at the outset of the study to ensure all involved are clear. Authors should also explicate their roles within articles so readers are able to discern the contributions of each individual to the IPE initiative and its related research, as currently required by some (yet not all) journals [16].

Further, a majority of studies conducted were either mixed-methods or quantitative designs. Although there are benefits to each type of design, there is an opportunity to expand the use of qualitative designs in IPE research, as this type of study design may be better positioned to elucidate the human experience. In addition, almost all studies included measures of student perceptions with some also studying faculty perceptions. While it is important to understand how students feel and their attitudes towards IPE, there is a clear lack of focus on IPE effectiveness. This is especially important in light of the multidisciplinary edge effect, as students need to understand both their own discipline and the traditions of others to optimize the healthcare system. Without assessing the effectiveness of IPE, we may be unable to capitalize on the generative potential of working with individuals from other disciplines, which is a key tenant necessary for the multidisciplinary edge effect to occur.

Moreover, where scholars submit and publish their research can influence its visibility and reach. Approximately half of IPE articles in this review were disseminated through interdisciplinary journals, suggesting that individuals who prioritize reading discipline-specific journals may miss findings from relevant IPE initiatives. This is especially important for professionals in medicine, nursing, and pharmacy, as less than $15 \%$ of IPE articles were published in each of these individual disciplines' field-specific journals even though these disciplines produced over $50 \%$ of the IPE research. In contrast, IPE journals build capacity for publishing IPE findings and expand opportunities for IPE scholars to disseminate findings. Strategies that ensure IPE research, from both discipline-specific and IPE journals, is visible to the relevant professions could be an important step towards advancing IPE initiatives.

We found the largest growth in IPE research was in the most recent year of the study, suggesting that IPE research is continuing to expand. This review gives way to numerous questions that could help elucidate IPE further as this body of research grows and as similar reviews are conducted across more recent years. For example, how is authorship and authorship order determined in IPE research, and why might some professions be less commonly represented as first or last authors? Since different disciplines have varying standards and expectations for authorship order [16], the interdisciplinary nature of IPE research offers unique authorship challenges - and some might suggest that who leads analysis and writing could be associated with who needs the manuscript for promotion, rather than those driving or contributing to the IPE in certain ways [29]. Second: why, and in what cases, are students from a discipline engaged in a study without an author from that discipline? Third: what incentives for IPE research exist within and between various health professions? Fourth, and related: to what extent are faculty incentivized to engage in SoTL and what mechanisms influence engagement as scholars in IPE?

Page $11 / 17$ 
Fifth: to what extent are IPE studies reaching appropriate stakeholders in light of current publication practices in IPE?

\section{Limitations}

As with any systematic review, this study has several limitations. First, the databases used in this search were domain specific. While it is possible the review missed some relevant articles, diverse databases from education and health professions were used to minimize this risk. Second, the review focused on work using the phrase "interprofessional education," which may have excluded articles with related terms. Third, publication bias may limit which IPE initiatives were published, as studies with statistically significant results are more likely to be published and cited within the literature [30]. While the limitations associated with publication bias could not be addressed in this study, the authors advocate for more transparency in IPE, including the dissemination of research resulting in negative or non-significant findings. Finally, this study did not analyze the nature of the studies that were reported, specifically, whether they were program evaluation studies or student self-reports on evaluations.

Despite these limitations, this review provides insight into the IPE research to-date, highlights potential opportunities for future research practices, and informs the development of an IPE research agenda for health professions education. Further research must be conducted to better understand the impact and utility of various research practices in IPE, how IPE research is incentivized and operationalized (e.g. authorship), and how these practices influence the extent to which we understand the impact of IPE on learners. Promoting the use, evaluation, and dissemination of IPE initiatives, and improving transparency in IPE research, is imperative for advancing collaborative care models within a rapidly evolving healthcare system.

\section{Conclusion}

IPE research can elucidate strategies for promoting the skills students must develop for success within a rapidly evolving and highly collaborative healthcare system. Since the WHO declared IPE a priority in 2007, health professions have increased their engagement in IPE research. However, variation between how differing professions approach IPE research, apparent mismatches in author and student disciplines, and varied publication practices raise some questions about IPE research practice. In light of this study, health professions must pursue IPE research that is inclusive and accommodating of scholars from various professions, fosters collaboration between traditional and emerging health professions, and positions students for success within a collaborative healthcare environment.

\section{Abbreviations}

EMBASE - Excerpta Medica

ERIC - Education Resources Information Center 
IPE - Interprofessional Education

MEDLINE - Medical Literature Analysis and Retrieval System Online

SoTL - Scholarship of Teaching and Learning

WHO - World Health Organization

\section{Declarations}

Ethics approval and consent to participate - Not applicable.

Consent for publication - Not applicable.

Availability of data and materials - The datasets generated and/or analysed during the current study are available in the PubMed (https://pubmed.ncbi.nlm.nih.gov/), SCOPUS (www.scopus.com), PsycINFO (https://www.apa.org/pubs/databases/psycinfo/index), EMBASE (www.embase.com), MEDLINE (https://www.nlm.nih.gov/medline/index.html), and ERIC repositories (www.eric.ed.gov).

Competing interests - The authors declare that they have no competing interests.

Funding - There was no funding for this study.

Authors' contributions - AO collected all data, lead the analysis, and drafted the manuscript. CLS contributed to data analysis and critical review and revision of the manuscript. GBD contributed to critical review and revision of the manuscript. JEM oversaw all aspects of the study and provided critical review and revision of the manuscript. All authors read and approved the final manuscript.

Acknowledgements - The authors would like to acknowledge UNC Health Sciences Library, Joe Yi, and Erica Bell for their help with this review.

\section{References}

1. World Health Organization. Framework for action on interprofessional education and collaborative practice. Geneva, Switzerland: World Health Organization 2010.

2. Reeves S, Zwarenstein M, Goldman J, Barr H, Freeth D, Koppel I, \& Hammick M. The effectiveness of interprofessional education: Key findings from a new systematic review. J Interprof Care. 2010:24(3);230-241.

3. Courtenay M. Interprofessional education between nurse prescribing and medical students: A qualitative study. J Interprof Care. 2013:27;93-95.

4. Taylor D, Yuen S, Hunt L, Emond A. An interprofessional pediatric prescribing workshop. Am J Pharm Educ. 2012;76(6):111. 
5. Zwarenstein M, Rice K, Gotlib-Conn L, Kenaszchuk C, Reeves S. Disengaged: A qualitative study of communication and collaboration between physicians and other professionals on general internal medicine wards. BMC Health Serv Res. 2013;13:494.

6. El-Awaisi A, Joseph S, El Hajj MS, Diack L. A comprehensive systematic review of pharmacy perspectives on interprofessional education and collaborative practice. Res Social Adm Pharm. 2018;14(10):863-882.

7. Olson R, Bialocerkowski A. Interprofessional education in allied health: A systematic review. Med Educ. 2014;48(3):236-246.

8. Visser CLF, Ket JCF, Croiset G, Kusurkar RA. Perceptions of residents, medical and nursing students about interprofessional education: A systematic review of quantitative and qualitative literature. BMC Med Educ. 2017;17(1):77.

9. <background-color:\#BCBCBC;uvertical-align:super;>Varpio</background-color:\#BCBCBC;uverticalalign:super;><uvertical-align:super;></uvertical-align:super;><background-color:\#DDDDDD;uverticalalign:super;>L</background-color:\#DDDDDD;uvertical-align:super;><uvertical-align:super;>, </uvertical-align:super;><uvertical-align:super;></uvertical-align:super;><backgroundcolor:\#BCBCBC;uvertical-align:super;>MacLeod</background-color:\#BCBCBC;uvertical-align:super;> <uvertical-align:super;>,</uvertical-align:super;><uvertical-align:super;> </uvertical-align:super;> <background-color:\#DDDDDD;uvertical-align:super;>A.</background-color:\#DDDDDD;uverticalalign:super;><uvertical-align:super;></uvertical-align:super;><background-color:\#CCCCFF;uverticalalign:super;>Philosophy of science series: Harnessing the multidisciplinary edge effect by exploring paradigms, ontologies, epistemologies, axiologies, and methodologies $</$ backgroundcolor:\#CCCCFF;uvertical-align:super;><uvertical-align:super;>.</uvertical-align:super;><uverticalalign:super;></uvertical-align:super;>Acad Med. doi: 10.1097/ACM.0000000000003142

10. Eisner EW. Forms of understanding and the future of educational research. Educ Researcher. 1993;22(7):5-11. https:// doi.org/10.3102\%2F0013189X022007005

11. Institute of Medicine. Measuring the impact of interprofessional education on collaborative practice and patient outcomes. Washington, DC: The National Academies Press;2015.

12. Brownlee JL, Ferguson LE, Ryan M. Changing teachers' epistemic cognition: A new conceptual framework for epistemic reflexivity. Educ Psychol. 2017;52(4):242-252.

13. Doolittle PE. Complex constructivism: A theoretical model of complexity and cognition. Int $\mathrm{J}$ Teach Learn Higher Educ. 2014;26(3):485-498.

14. Kuhn D, Weinstock M. What is epistemological thinking and why does it matter? In: Hofer BK, Pintrich PR, ed. Personal epistemology: The psychology of beliefs about knowledge and knowing. Mahwah, NJ: Lawrence Erlbaum Associates Publishers; 2002:121-144.

15. National Center for Education Statistics. (2018). Fast facts. Retrieved from https://nces.ed.gov/fastfacts/display.asp?id=167

16. Minshew LM, McLaughlin JE. Authorship considerations for publishing in pharmacy education journals. Am J Pharm Educ. 2019;83(6):7463. 
17. Thistlewaite J. Interprofessional education: 50 years and counting. Med Educ. 2016;50(11):10821086.

18. Hoffman SJ, Rosenfield D, Gilbert JH, Oandasan IF. Student leadership in interprofessional education: Benefits, challenges and implications for educators, researchers, and policymakers. Med Educ. 2008;42(7):654-661.

19. World Health Organization. Learning Together to Work Together. Geneva, Switzerland: World Health Organization 1988.

20. Paradis E, Pipher M, Cartmill C, Rangel JC, Whitehead CR. Articulating the ideal: 50 years of interprofessional collaboration in Medical Education. Med Educ. 2017;51(8):861-872.

21. Bell HT, Granas AG, Enmarker I, Omli R, Steinsbekk A. Nurses' and pharmacists' learning experiences from participating in interprofessional medication reviews for elderly in primary health care: A qualitative study. BMC Fam Pract. 2017;18(30).

22. Lawlis TR, Anson J, Greenfield D. Barriers and enablers that influence sustainable interprofessional education: A literature review. J Interprof Care. 2014;28(4):305-310.

23. Brazeau GA, Meyer SM, Belsey, M, Bednarczyk E.M., Bilic S, Bullock J, DeLander GE, Fiese EF, Giroux SL, McNatty D, Nemire R, Prescott WA, Traynor A. Preparing pharmacy graduates for traditional and emerging career opportunities. Am J Pharm Educ. 2009;73(8):157.

24. Martin C. Reconstructing a lost tradition: The philosophy of medical education in an age of reform. Med Educ. 2012;47(1):33-39.

25. Smesny AL, Williams JS, Brazeau GA, Weber RJ, Matthews HW, Das SK. Barriers to scholarship in dentistry, medicine, nursing, and pharmacy practice faculty. Am J Pharm Educ. 2007;71(5):91.

26. Morahan PS, Fleetwood J. The double helix of activity and scholarship: Building a medical education career with limited resources. Med Educ. 2008;42(1):34-44.

27. Baerlocher MO, Newton M, Gautam T, Tomlinson G, Detsky AS. The meaning of author order in medical research. J Investig Med. 2007;55(4):174-180.

28. Uijtdehaage S, Mavis B, Durning SJ. Whose paper is it anyway? Authorship criteria according to established scholars in health professions education. Acad Med. 2018;93(8):1171-1175.

29. Tarkang EE, Kweku M, Zotor FB. Publication practices and responsible authorship: A review article. J Public Health Afr. 2017;8(1):723.

30. Dwan K, Altman DG, Bloom J, Chan AW, Cronin E, Decullier E, Easterbrook PJ, Von Elm E, Gamble C, Ghersi D, loannidis JP, Simes J, Williamson PR. Systematic review of the empirical evidence of study publication bias and outcome reporting bias. PLoS One. 2008;3(8):e3081.

\section{Figures}




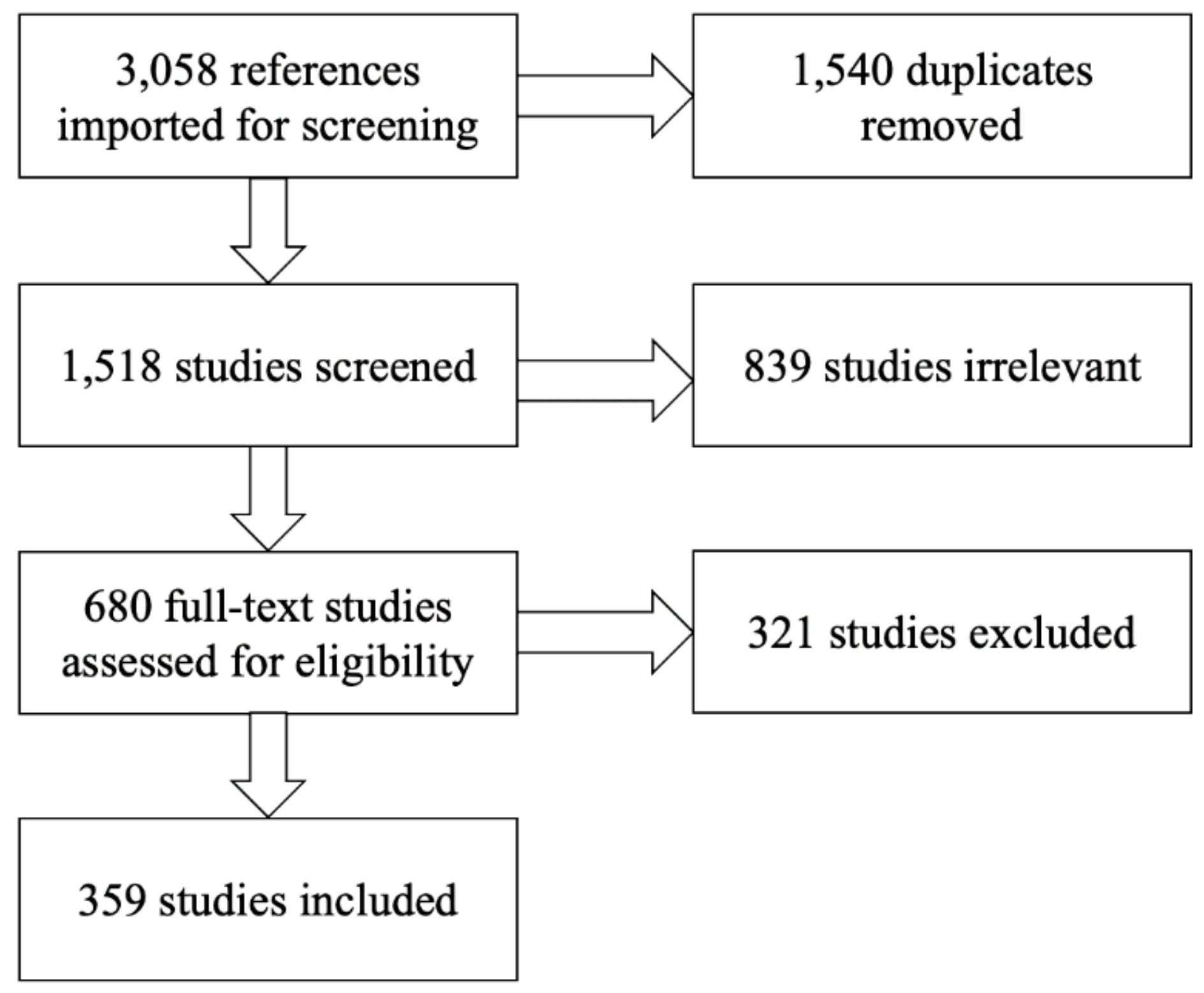

Figure 1

Study Selection Diagram for IPE Articles Published between 2008 and 2018 
100

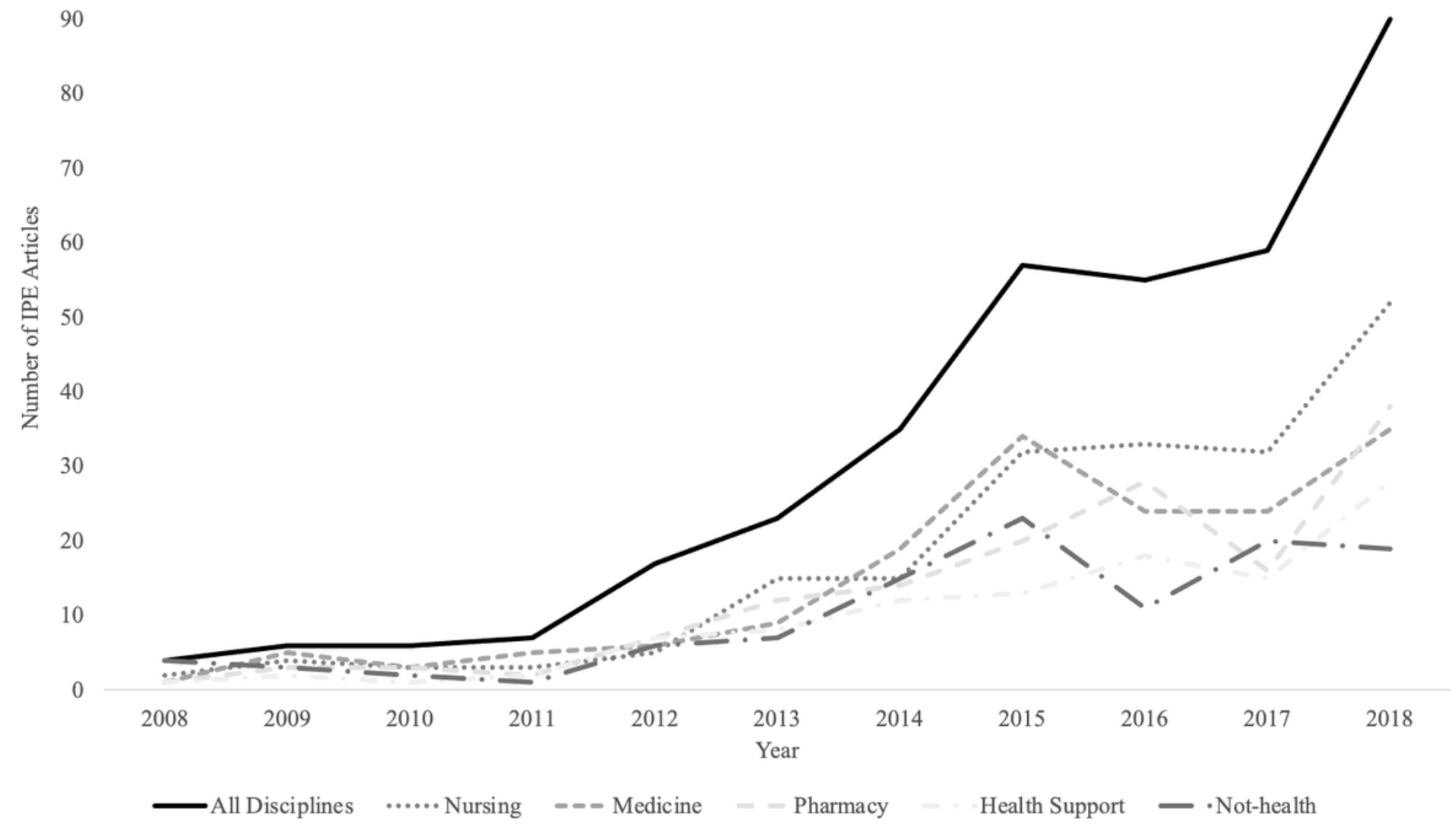

Figure 2

Number of IPE Publications, by Year, for the Most Frequent First Author Disciplines 